\title{
Design of Popular Science Toys Based on Children's Growth Cognition Law
}

\author{
Hong-he Gao ${ }^{1}$, Xiao-cheng Xing ${ }^{1}$, Jin-hua Fu \\ ${ }^{1}$ School of Art\&design, Liaoning Shihua University, Fushun, Liaoning,113001, China
}

\begin{abstract}
China is a big consumer of toys. With the opening of the country's two-child policy and parents pay more and more attention to children's education, the toy market is becoming increasingly popular. Toys are important playmates in children's growth and play an important role in children's intellectual development and early education. However, at present, children's toys are mostly educational toys, which only inspire children's intelligence, stimulate children's brain activity and develop children's intelligence. However, systematic popular science toys for children are relatively lacking, and relevant research materials are also few, which do not play a good role in enlightening children's popular science. According to the design principles and methods of children's toys, aiming at the shortcomings of the existing popular science toys for children, through in-depth investigation and analysis of popular science toys for children, this paper organically combines children's toys with popular science, and makes some design attempts. The aim is to change the current situation that many students have a certain fear of physics and chemistry in high school due to the lack of popular science knowledge in childhood.
\end{abstract}

\section{Introduction}

The healthy growth of children is related to the family, society, nation and even the future and destiny of a country. ${ }^{[1]}$ childhood is a critical period of life. It is a critical period to cultivate children's knowledge, thinking, behavior, cognition and other abilities, which will directly affect children's growth.Games are an important activity in childhood and play an important role in children's growth.As the carrier of games, toys can enable children to know unknown things in play, exercise children's hand and brain coordination ability, inspire wisdom and help children learn plasticity in the future. With the development of social economy and the two-child policy, the proportion of children's toys in China's consumer spending has been increasing year by year.In the whole school stage, especially in the schoolage stage, toys are the close playmates of children, playing the role of teachers and helpful friends who lead them to know the world in their growing process, which makes toys the indispensable necessities of children's growing stage.

\section{Overview of science toys for children}

Children's toys refer to toys designed, processed, and sold, as made clear by the manufacturer, exclusively for children ${ }^{[2]}$. In general, children's toys are designed for children of a specific range of ages, and are closely related to the children's age and IQ development stage, taking into consideration the children's adaptability. Children's toys are no longer gadgets that serve the purpose of mere fun, but products that can lead the children to learn, interact positively with the children and increase the children's attachment to the toys. Children's toys should first be educational and then be instrumental to children's development. This means in the design of children's toys; the designers and manufacturers should consider the pattern of children's development and extend the products' functionality. Therefore, science toys for children should be both entertaining and learning-encouraging. The purpose of science toys is to develop the children's intelligence while, with toys as an effective tool, let the children enjoy the play and absorb science knowledge unwittingly, thus realizing popularization of science. In other words, the science toys will let children learn in play, and play in learning activities.

\section{Market for children's toys and research status quo}

\subsection{Current market for children's toys.}

\subsubsection{Current market for children's science toys in China.}

As the competition in the children's toys market grows, more toy manufacturers seek to combine education and fun in their design of toys, but most pigeonhole 
educational toys into the category of traditional toys in their R\&D. What's worth a mention is that many building-brick toy brands in China have released toys that involve elements of programming, mechanics and physics in recent years ${ }^{[3]}$, which indicate the progress of Chinese educational toy manufacturers.

Science toys are education-oriented toys that combines technology, knowledge with playing. Chinese toy manufacturers, however, are short of talents in this regard, which lead to disproportionate quality of Chinese science toys, and most toys are mere imitations of their foreign counterparts, without diversity in the playing ways nor clear orientation for ages. The market survey for children's toys show that Chinese toy manufacturers invest little to science toys and there is no systematic planning for development of science toys.
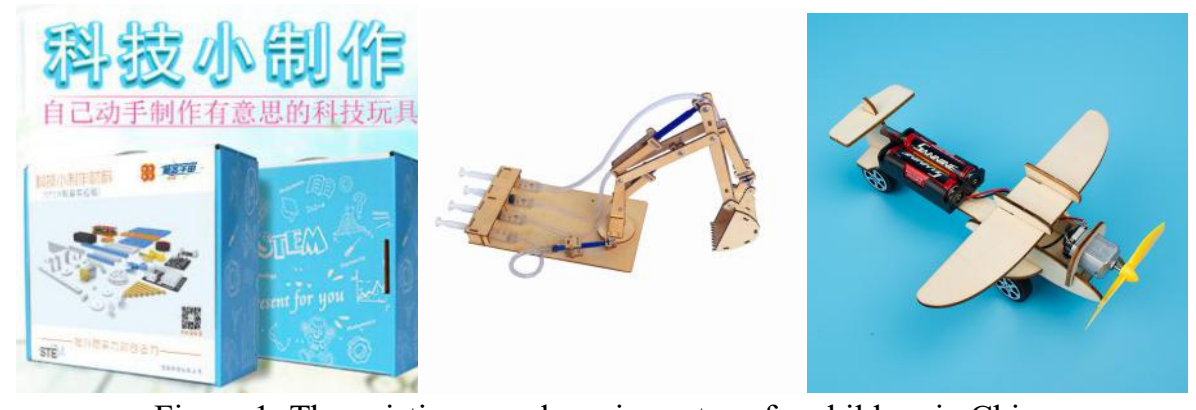

Figure 1: The existing popular science toys for children in China

\subsubsection{Current market of children's science toys in foreign countries.}

International giants for children's toys including the US, Europe and Japan have enjoyed global reputation with their children's toy brands, such as the US Mattel, the Japanese Takaa Tomy and the Denmark Lego. They have not only strong capital, leading toy designers, enviable marketing channels, but also a cutting edge over their competitors with their high-tech toys ${ }^{[4]}$. Children's toy manufacturers in foreign countries have clear market orientation and a mature system that connects the toys into a series. The toy designers abroad are worth learning from: they emphasize morphological innovation, insisting that it is an essential part of children's toys and that a toy must show novelty in morphology if it is to catch the children's attention. Science toys abroad also emphasize diversity in the ways of play, and with each mission in the game closely connected, the fun and playability of the game are extended.

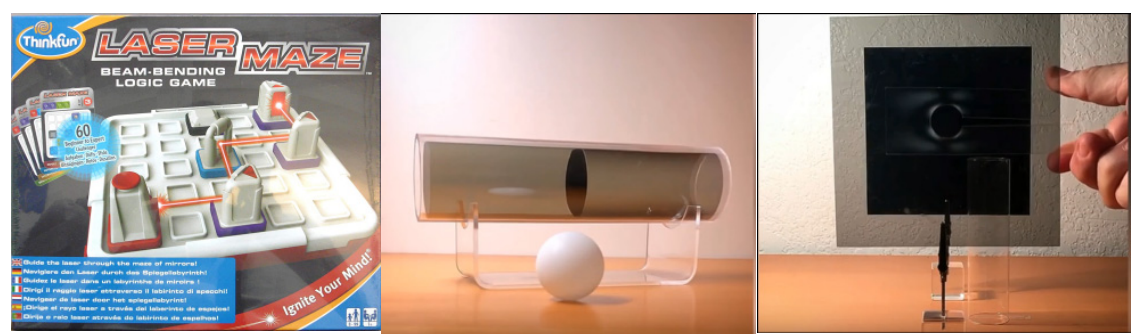

Figure 2: There are foreign popular science toys for children

Studies on children's science toys started earlier

\subsection{Research status quo on children's science toys in China}

In contrast with the children's toy market abroad that enjoy prosperity, the market in China has not been fully researched, and studies on science toys in China are particularly rare. So far, there are 3,834 papers on children's toys in China, a lot of which (443) are about educational toys, but merely 16 are about science toys, including 2 master's theses and 11 journal papers: the journal papers are on engineering economy, science and technology management, and the master's theses are from Tianjin University of Science and Technology and Beijing University of Chemical Technology. Chinese studies on children's science toys in China focus on the fields of design, art, aesthetics and marketing, and some others explore the technologies and design methods for children's toys; while few studies are based on the pattern of development of children's recognition. abroad, and they have established specific organizations to design science toys, injecting new blood to the industry constantly and adapting to the trend. In particular, the US, with a clear grasp of the market for children's science toys, have combined educational values with design of toys and increased the fun of these toys, thus winning popularity among both children and parents.

\section{Analysis of the development pattern of children's recognition}

\subsection{Division of age stages for children}

According to Jean Piaget's theory of cognitive development, the children's cognitive development is divided into the following stages: 0-2 years old: the sensorimotor stage; 2-7 years old: the preoperational 
stage; 7-11 years old: concrete operational stage, and 11 years old and above: the formal operational stage ${ }^{[5]}$. Also, in China's Children's Development Scale, the researchers have formulated the children's developmental characteristics that suit the Chinese children, including 11 items from four aspects - language, cognition, social cognition, and motion. Via expert verification and experiments, evaluation for cognitive development of children aged 3-6 provided a highly reliable tool. The measurement result shows that children's cognitive development is fast in this range of ages (Table 1) ${ }^{[6]}$. It means this period accounts for a critical period for children's cognitive development and this provides a clear age range for design of science toys.

(Table Source: CDDCC China Child Development Scale (3-6 years old)

\begin{tabular}{c|c|c|c|c|c|c}
\hline Test & $\begin{array}{c}\text { Social } \\
\text { cognitio } \\
\mathrm{n}\end{array}$ & observation & attention & $\begin{array}{c}\text { General } \\
\text { summarizing } \\
\text { ability }\end{array}$ & $\begin{array}{c}\text { calculatio } \\
\mathrm{n}\end{array}$ & $\begin{array}{c}\text { Language } \\
\text { expression }\end{array}$ \\
Naming the picture & 0.12 & -0.01 & 0.07 & 0.13 & 0.15 & $* 0.88$ \\
Use of quantifiers & -0.08 & 0.17 & $* 0.68$ & 0.02 & 0.36 & 0.23 \\
Complete the images & 0.03 & $* 0.08$ & $* 0.81$ & 0.24 & 0.01 & 0.08 \\
Language comprehension & 0.38 & $* 0.62$ & 0.21 & -0.03 & 0.21 & 0.01 \\
Find images by examples & 0.08 & $* 0.09$ & 0.07 & 0.17 & 0.07 & -0.02 \\
Grab objects in bags & 0.08 & 0.10 & 0.17 & $* 0.86$ & 0.00 & 0.29 \\
Jigsaw puzzles & 0.22 & 0.14 & 0.13 & $* 0.06$ & 0.44 & 0.37 \\
Counting and calculating & 0.12 & 0.19 & 0.11 & 0.07 & $* 0.78$ & 0.19 \\
Mistake analysis & $* 0.78$ & 0.20 & 0.22 & 0.00 & 0.00 & 0.10 \\
Social common sense & $* 0.63$ & 0.27 & 0.36 & 0.11 & 0.16 & 0.05 \\
Personal relations & $* 0.74$ & -0.05 & -0.11 & 0.26 & 0.43 & -0.01 \\
\hline
\end{tabular}

\subsection{Analysis of cognitive development of children aged 3-6}

As Table 1 shows, children's cognitive development is fast when they are 3-6 years old, and this age range is in the preoperational stage, during which the children have a larger range of activities, strong desire for knowledge, strong imagination, and eagerness to know the world. They are willing to make things by their own hands or do small experiments. Their intellectual and mental status improves in this period and their personality is shaping. The period between 3 and 4 years old sees rapid cognitive development and is called the "black-hole period". In this period, children can tell large from small, long from short, high from low, more from less; they can identify their own marks and enjoy perceiving the world with their senses. They have rich imagination, curiosity, and thirst for knowledge. Imitation is their major way of learning in this period. Some concepts begin to shape in their minds. They are willing to try, to think in order, to play along with others, to raise questions and want to explore.

The purpose of finding the cognitive development pattern of children is to provide a scientific basis for design of science toys. Science toys can help tap the children's potential and play an enlightening role in advancing the children's creativity, hands-on skills, independent thinking, and linguistic capacity. Playing toys is a way the children interact with the outside world, and when playing the science toys, they understand the knowledge and the toys, which sends stimuli to their cerebral cortex and create connection between knowledge and everyday life, laying a foundation for further learning activities.

\section{Design of science toys based on children's cognitive development pattern}

\subsection{Principles for design of children's science toys}

\subsubsection{Education Principle}

Kathleen Alfano holds that "However different the modern-day toys seem from those in ancient times, the aim of children's toys remains unchanged: to bring laughter to children and provide opportunities for learning and development [7]". In other words, when designing science toys, we should try to motivate the children, cultivate their hands-on skills, their problemsolving skills, expand their thinking, and train their sense of logic. Science toys should be both fun and interesting; and children can expand or re-create the science toys as their imagination allows.

\subsubsection{Safety principle}

Children aged between 3 and 6 already have their own consciousness, but they still belong to the disadvantaged group, so safety is a must. The shape and materials of science toys should meet the safety standards, and given the possibility of disoperation in playing these toys, the harm of the science toys should be reduced to the minimum. 


\subsubsection{Interest principle}

Children aged between 3 and 6 develop very fast and have strong curiosity about new things. They also have short attention spans and will lose interest in a toy if they play it for long. Thus, toy designers should use bright colors and beautiful shapes to attract their attention, and consider of extensibility and systematic functions of the toys during their design.

\subsubsection{Human-machine interaction}

Every toy should be user-oriented when it is designed, so the user's characteristics should be fully considered during the design. Children in this period are in the critical period for training of refined movements of hands [8]. Therefore, the designers should consider how to train the children's grasp ability and their sensitivity to shapes and colors when designing the toys.

\subsection{Design methods}

\subsubsection{Sorting the knowledge points using mind maps}

Creating mind maps is a technique that uses both images and texts, presenting the relations of different levels using layered structures to help balance science and art, logic, and imagination; it is a creative and effective notemaking method. Designers can sort the science knowledge that the science toys involve by mind maps, extend the game based on the phenomena, principles and nature of mechanics (Figure 3), and present the mechanical phenomena one by one, find the correlations between knowledge points, to find the direction for design of children's science toys.

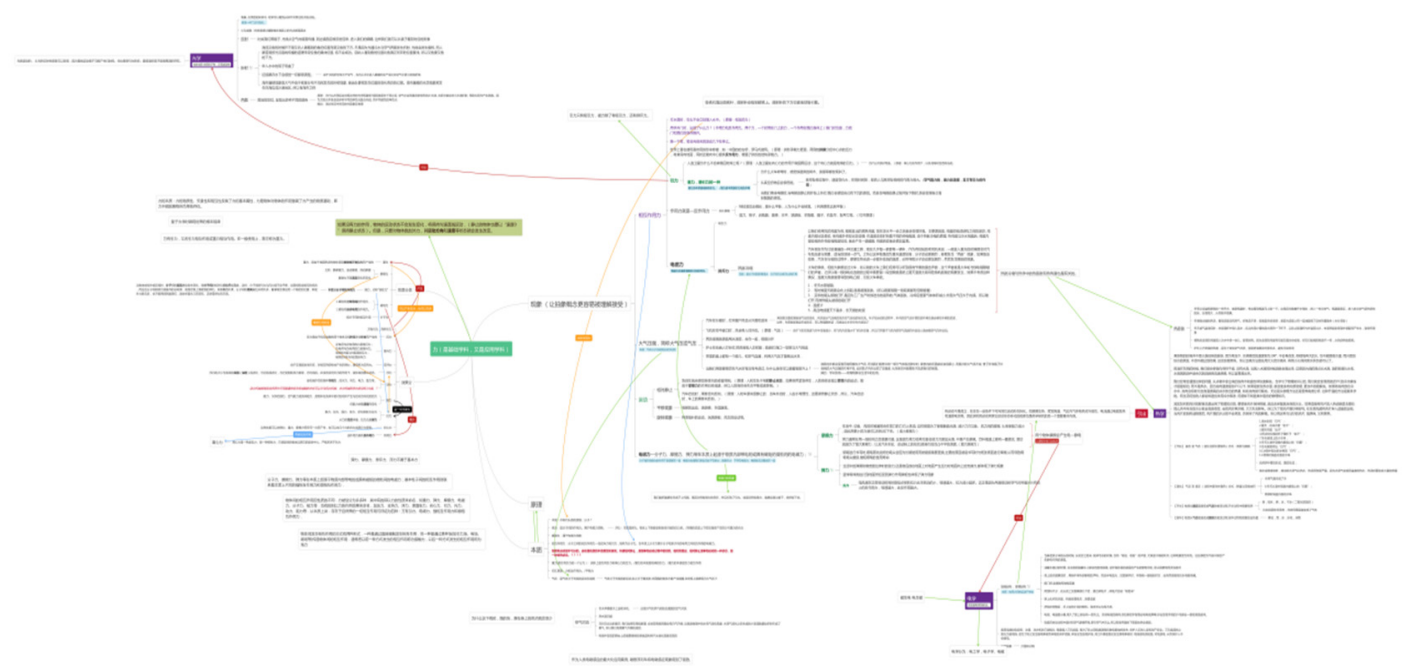

Figure 3: Mind Map of Children's Popular Science Content

\subsubsection{Using a product matrix to find the starting point of design}

According to the combination methods of TRIZE theory, we should first define the problems before solving them, and the more clearly they are defined, the larger the chances are to solve them. Thus, the cognitive development pattern and influencing factors are sequenced (Figure 4) to identify the knowledge points of children aged between 3 and 6; meanwhile, the features of science toys are also sequenced to perform cross comparison. Meaningful crossing points are found to provide a starting point for design of science toys. 


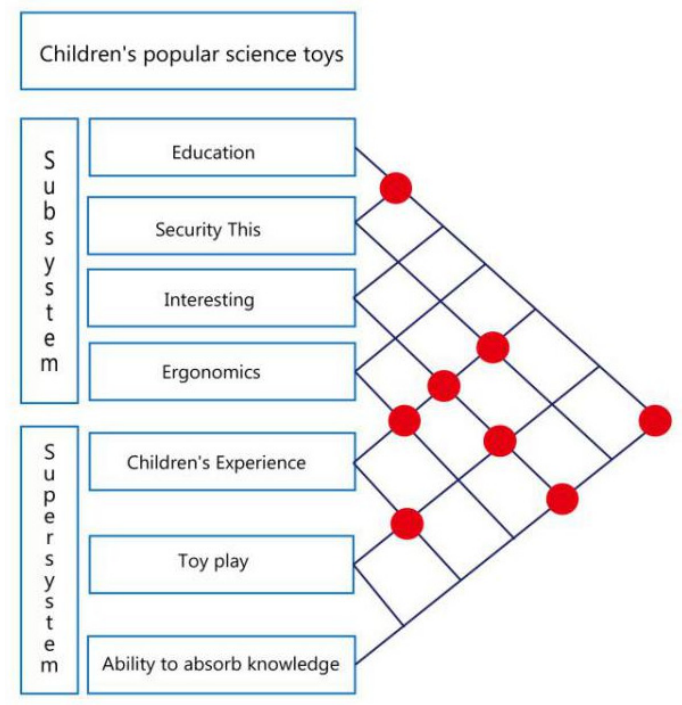

Figure 4: Children's Popular Science Toys

\subsection{Design process}

Above analyses show that mechanics involves both physics and mathematics, and is present in our everyday life. Therefore, mechanics is taken as the starting point. At the start of design, we should consider what specific knowledge of mechanics should be imparted. The mind maps show that friction is a common force in life and allows extension of other related knowledge. The factors related to friction lead the designers to find the crossing points, so that they can design the science toys into a systematic series, and each toy in this series is correlated and extensible.

Also, based on the TRIZ theory, a matrix based on the combination methods is built (Figure 4). It shows that designers of children's science toys should consider education and the children's experience in their design, and should make sure that children can take in the science knowledge during the play unwittingly. Thus, design of science toys should be systematic.

The final design plan is as follows(Figure5).

The "Beat \& Strike" science toy: this toy aims to allow the children learn that the frictions between different materials differ. The selected materials include wood, rubber, plastic, leather, etc., which all meet the safety standards for children. For children aged between 3 and 6 , this toy is not only entertaining, but easy to accept. The toy is simplified as much as possible in shape, and bright colors are used to attract the children. The children's hand grasp features are considered in the design of this toy so that the children can pick up or place the toys easily. Different shapes are used; when the parts fall as the children beat or strike, they then place them back to recessions of corresponding shapes, which will train the children's grasp capacity and their sensitivity to colors and shapes. For parts of irregular shapes, the materials and texture differ. When the children touch the parts, they have different feelings, and the sounds emitted when the children beat or strike send stimuli to the children's ears, allowing them to learn that the friction differs as the materials vary. The children can also rub

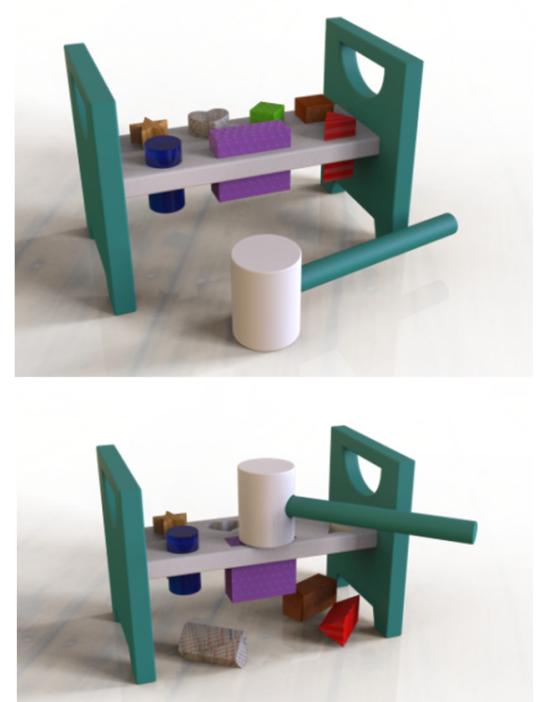

Figure5: The "Beat \& Strike" science toy two different shapes as they will, or rub a cube against anything at home to feel the difference in friction among different materials.

\section{Conclusions}

Science toys for children aged between 3 and 6 are taken as the object of study; by analyzing the cognitive development pattern of children in this age range and by following certain design principles, we proposed the idea of systematic design of children's science toys based on their cognitive development pattern, which would allow children grasp knowledge unwittingly, achieve intellectual and mental wellbeing, and learn in fun. All toys for children should be based on children's cognitive development pattern and achieve the goal of all-round development of children.

\section{References}

1. Yu-yue L. (2017) Design and Research of Popular Science Toys to Improve Pupils' Cognitive Ability. Tianjin University of Science and Technology.

2. Provisions on the Administration of Recall of Children's Toys (Order No.101 of the State General Administration of Quality Supervision, Inspection and Quarantine). Product Quality and Safety Supervision and Administration Department Network of the State General Administration of Market Supervision and Administration [Citation Date 2019-10-28]

3. Yue M. (2019) Three key points to leverage the big market for educational toys. Toy Manufacturing at Home and Abroad., (10):13-15.

4. Hua-wei L. (2010) Comparative Study on Design of Chinese and Foreign Children's Toys. Kunming University of Technology.

5. Qiang L., Ming G.(2010) Educational Psychology, Beijing Publishing House.

6. [6] Rong Z., Hou-can Z.(1994) Development of CDCC China Child Development Scale (3-6 years 
old) [J]. Psychological Science., (03):137$140+132+192$.

7. Yi-fang G.(2015) Explore the application of psychological cognitive development theory in children's toy design. East China Normal University.

8. Zi-ran Z.(2019) Application of Emotional Design Theory in Children's Toys [J].Design., 32(11):20-22. 